\title{
EDUCAÇÃO INTEGRAL: UM DIREITO DE TODOS
}

Sousa Santos Sebastiao ${ }^{1}$

\begin{abstract}
RESUMO
Este artigo tem como objetivo refletir sobre a relevância da educação integral baseado em um importante documento da UNESCO em 2016. A metodologia usada foi por meio de fonte bibliográfica e as contribuições deixadas pelos autores que defenderam essa relevante temática. Os resultados dessa pesquisa têm como finalidade verificar a real importância da criação e da inserção de uma educação integral que vise formar um indivíduo pleno. A conclusão desse artigo é perceber o quanto a nossa educação formal necessita de sérias reformulações.

Palavras-chave: Educação. Políticas. Valores. Princípios.
\end{abstract}

\section{INTEGRAL EDUCATION: A RIGHT OF EVERYONE}

\begin{abstract}
This article aims to reflect on the relevance of integral education based on an important UNESCO document in 2016. The methodology used was through a bibliographic source and the contributions left by the authors who defended this relevant theme. The results of this research aim to verify the real importance of the creation and the insertion of an integral education that aims at forming a full individual. The conclusion of this article is to realize how much our formal education needs serious reformulations.
\end{abstract}

Keywords: Education. Policies. Values.Principles.

\section{INTRODUÇÃO}

Ao recorremos ao dicionário Aurélio (2009), encontramos o seguinte significado para a Educação Integral como uma concepção que compreende que a educação deve garantir o desenvolvimento dos sujeitos em todas as suas dimensões - intelectual, física, emocional, social e cultural.

Em meio a tantos desafios na educação contemporânea, construir uma educação que seja, de fato integral é um grande desafio a ser atingido, que requer um minucioso trabalho de intervenções dentro das mais diversas realidades que temos. Alicerçado nisso, o problema desse artigo consiste em analisar o processo de formação educacional, tendo como base teórica documentos expostos pela Organização das Nações Unidas para a Educação, a Ciência e a Cultura (UNESCO) 2016. Documento esse de grande relevância para a educação mundial intitulado de Repensar a Educação. Rumo a um bem comum mundial? Este documento consiste em uma obra preciosa, onde descreve os desafios para a educação do século XXI, apontado ainda caminhos, a serem seguidos em prol de uma educação mais significativa e integradora.

\footnotetext{
${ }^{1}$ Faculdade de Tecnologia e Ciências
} 
O desafio é formar passo a passo uma educação integral que tem o significado de promover um ambiente de ensino com a característica de pluralidade, onde sejam priorizados os princípios e valores éticos, tão necessário para formação da sociedade e da cidadania.

O trabalho está dividido em quatro partes principais, sendo a primeira parte uma pequena síntese sobre fatos e aspectos relevantes que estão contidos no documento da UNESCO (2016). Expondo as muitas necessidades existentes dentro do contexto educacional, em prol de uma educação integradora, que contemple os principais pilares educacionais.

Seguidamente o trabalho passeia pela educação moral mostrando a sua relevância para a construção de uma sociedade mais digna e humana. É feito ainda uma relação sobre a importância da psicologia do desenvolvimento de acordo com os estudos de Kohlberg (1992).

A educação é um direito de todos e para todos, porém muitos ainda estão às margens da exclusão educacional. No entanto o foco principal aqui é discutir o conceito de uma educação responsável e integral.

Assim, são discutidos os diferentes posicionamentos de autores que esboçam teorias e conceitos referentes a uma educação integral, uma realidade que já era pra ser algo concreto dentro do sistema público de ensino, e ainda enfrenta muitas desigualdades e contrastes sociais.

Num terceiro momento é explanado aqui, que a educação que tanto se almeja construir, só será de fato efetivado, quando houver uma soma positiva de forças, em prol de um objetivo prioritário e comum: A construção de uma educação muito mais integral.Por ultimo, são apresentados os resultados e benefícios que a educação integral, tem dado em algumas escolas e municípios que adotaram essa importante modalidade.

Nessa importante construção e reconstrução, é imprescindível que haja as condições básicas e com o auxilio necessário dos recursos humanos, financeiros e pedagógicos para que tenha o alicerce base, para esse tipo de educação que se objetiva construir. Dentre muitas outras ações e intervenções que devem está intimamente relacionadas são incluídas a sustentabilidade da vida no planeta, uma causa mais do que nobre, já que a sociedade global vive sob ameaças ambientais.

Dentro desse grande desafio de uma educação integral o objetivo aqui é buscar por respostas satisfatórias que sirva de amenização para o problema aqui citado. O recurso metodológico aqui apresentado com uma breve análise de obras que traz essa temática tão pertinente para a atualidade. 
Partindo para o objetivo geral que aqui se almeja alcançar, o estudo visa refletir sobre a relevância da educação integral dentro das práticas educativas que permeiam o processo de ensino aprendizagem. Tendo ainda, três objetivos específicos: Detalhar pontos pertinentes que a UNESCO expõe sobre a educação integral; Relacionar alguns aspectos da educação integral com a realidade que temos; Mostrar a necessidade da construção de uma educação moral, ética e sustentável na formação do sujeito muito mais pleno.

Assim, o objeto de pesquisa é a construção em si, de uma educação muito mais integradora, sendo o eixo central de nossa investigação, despertando a nossa atenção para essa necessidade. As hipóteses dessa pesquisa estão voltadas para os seguintes questionamentos: Como construir uma educação mais integral?De que modo esse processo ocorre? Por que se faz tão necessário essa construção? A pesquisa está fundamentada, principalmente, nas propostas da UNESCO (2016), Sgró (2007), Kohlberg (1992) e Freire (2005). Enquanto que a metodologia utilizada é uma abordagem qualitativa, através de uma pesquisa bibliográfica, por meio de um método dedutivo, pois usam de forma interdisciplinar diferentes aspectos apontados pelos autores que expõe seus posicionamentos.

Os pressupostos dessa pesquisa estão voltados para as mudanças que devem ocorrer dentro do sistema educacional, para que seja alcançado aquilo que sonhamos concretizar que é um ensino muito significativo e com maior equalização escolar. Como recursos aplicados foram utilizados o levantamento bibliográfico, tendo como a interpretação de teoria que abordam essa temática.

Indo para o procedimento técnico, esse estudo tem como característica a pesquisa será bibliográfica e documental além, de contar com o apoio de outras fontes como sites de pesquisas.

\section{DISCUSSÕES EDUCAÇÃO INTEGRAL}

Mas o que é de fato uma educação integral? Essa importante resposta é dada pela própria UNESCO (2016). É o processo educacional onde deve ser garantido o desenvolvimento de certas habilidades e competências que são necessárias para a formação da identidade e do caráter do sujeito de forma ampla e significativa. Fundamentado nisso a UNESCO (2016), por meio do documento "Repensar a Educação. Rumo a um bem comum mundial"? Documento esse que hoje recebe o titulo de patrimônio educacional, expõe as políticas públicas educacionais, que consiste em um importante conjunto de ações e intervenções, que são necessárias para a consolidação de educação mais integradora. 
Para a UNESCO (2016), a educação é de responsabilidade de todos, mesmo sabendo que existe o grande equivoco, em pensar que essa responsabilidade é de governos e órgãos competentes, professores e escolas. Então, é necessário que haja um minucioso trabalho de desconstrução, acerca desse pensamento errôneo, que foi criado e que vem se perpetuando, ao longo dos anos, sendo mais do que necessário o seu combate.

A educação sendo ela a integral ou não, é um órgão vivo e deve ser dada a real prioridade que ela requer, e essa responsabilidade não é de $\mathrm{A}$ ou $\mathrm{B}$ é de todos, porque educação é sinônimo de pluralidade e diversidade. O significado do termo educação é amplo e engloba muitos conceitos e definições sendo, um deles a responsabilidade pelo processo formativo, que envolve a aprendizagem de teorias cientificas e a aprendizagem de princípios e valores morais também.

A educação com responsabilidade integral pode ser definida de diferentes maneiras, uma delas consiste em uma metodologia especifica, que segue um rigoroso planejamento, associado com o apoio dos recursos básicos para que dê todo o suporte que é necessário para a sua consolidação.

Mediante ao documento da UNESCO (2016), diz que para a formação de uma educação integral é preciso que aconteça na prática, uma abordagem holística tanto para o termo educação como para a aprendizagem, que está sendo passo a passo construída. Esse termo abordagem holística significa de forma simplificada o desenvolvimento da capacidade racional e emocional do sujeito, dois pontos chaves de estrema importância para constituir o sujeito: $\mathrm{O}$ chamando processo de humanização.

Um grande desafio que deve ser superado, com garra e estratégias bem estabelecidas. Ainda dentro do campo da abordagem holística devem ser consideradas ações, atitudes e comportamentos que sirvam de caminhos para a formação da sociabilidade, uma vez que o homem é um ser social.

Ainda de acordo com o documento da (UNESCO, 2016), as abordagens holísticas são essências, no que se refere à construção de uma educação integral, pois ela atinge o bemestar físico e intelectual do sujeito, passeando por partes específicas do cérebro humano que são as chamadas interações emocionais e cognitivas do sujeito. Fundamentado nisso surge à necessidade que seja trabalhada, com maior responsabilidade dentro do contexto escolar a abordagem de uma educação que também seja holística, ou seja, uma educação humanizadora e humanizada.

Analisando o contexto escolar na atualidade, o sistema de ensino sofre uma crise que é apontada por SGRÓ (2007), onde é exposto que a educação escolar na atualidade, tem RPI Revista de Pesquisa Interdisciplinar, Cajazeiras, v. 3, n. 2, p. 61-77, 2018. 
trilhado sem um direcionamento, sem um alvo a ser objetivado.Esse problema é um impedimento que torna a educação que temos hoje deficiente e com inúmeras lacunas.O autor conclui sua fala exortando que o processo educacional, devem conduzir crianças, jovens e adultos a um foco que deve ser traçado com objetividade e compromisso, a exemplo disso a aprendizagem integral.

O peso do termo educação é riquíssimo e, é pro meio dela que é construída toda uma sociedade e, se ela não tem qualidade, tão pouco essa sociedade terá. Porque educação e sociedade são dois termos indissociáveis. A educação é o alicerce para a construção de novas referências, que uma sociedade precisa para fluir positivamente, ela funciona como mola mediadora para os princípios e valores que os seres humanos necessitam, para vida em sociedade.

A grande carência na atualidade é resgatar o verdadeiro papel que a educação tem, já que em parte esse papel tem sido ao longo dos últimos anos usurpado ou deixado de lado, ou até mesmo negligenciado. Uma das soluções para amenizar esses problemas na atualidade é apontada por inúmeros teóricos como a implantação de políticas públicas, seguida de projetos políticos, sociais e econômicos que dê o suporte necessário para a formação e potencializem a constituição de uma educação com maior responsabilidade integral.

Assim, surge a necessidade de sérias e drásticas reformulações, no modelo educacional que temos na atualidade. Porque a Constituição Federal e a LDB que regem em parte a educação no país, já estão ultrapassados, necessitando de reformas e da inserção de uma visão mais inovadora e compatível com a nova realidade que temos.

De acordo com os quatro pilares que sustenta a educação, são necessários recorrer ao "aprender a fazer". Isso implica que a educação precisa de uma nova forma de ser executada, como um objetivo distinto e especifico a ser atingido. Combatendo o enraizamento do sistema educacional tradicionalista, dando maior espaço para ideias construtivista e que permita a construção de seres humanos com maior potencial de reflexão e criticidade, transformado positivamente sua realidade.

Dentro dessa linha de raciocínio (BANNWART JÚNIOR, et al. 2017), diz que a educação integral deve ser aquela que, seja capaz de construir um aprendizado transformador que atinja os aspectos individuais e sociais do sujeito.Isso inclui também o processo de humanização do sujeito.Os autores ainda expõem que o ensino para ser integral deve possuir um direcionamento, um alvo, um ideal.Quando não houver na prática, esses requisitos básicos a educação integral será algo infelizmente totalmente abstrata, e longe de se concretizar no 
nosso cotidiano.Isso não que dizer, que em leis, decretos e documentos oficiais, não tenha tais objetivos descritos, o problema é que o que está escrito, nem sempre condiz com a realidade que está sendo construída.

Ainda na visão de (BANNWART JÚNIOR, et al. 2017), é defendida a visão holística, com já foi citado anteriormente o seu valor é indispensável para a formação de um educação integral, porque ela vai de encontro aos valores sociais, morais e espirituais.Aqui os autores diz que a abordagem holística é contemplada pela integralidade, ou seja, essa visão, ou melhor dizendo esse modelo educacional consiste em desenvolver um olhar prioritário para as pessoas enquanto ser humano.Esse requisito de humanidade e afetividade é uma grande carência dentro do contexto educacional, sendo necessário o seu exercício continuo nos espaços de aprendizagens.Essa necessidade é também chamada de educação humanizada que tem o objetivo de educar e humanizar o sujeito, uma vez que o ser humano vem, sofrendo com o processo muito rápido de desumanização..

Diante dos estudos de Kohlberg (1992), a pedagogia da responsabilidade integral é um excelente componente de grande peso para formar um ensino integral na vida escolar do indivíduo, porque ela prioriza a autonomia individual.

Nesse sentido Freire (2005), afirma que o desenvolvimento individual está vinculado ao desenvolvimento cultural, social e ambiental. Isso nos faz lembrar a importância de um trabalho contextualizado, um item indispensável na construção de um ensino integral, sendo priorizados que seja cada aspecto trabalhado de forma continua e interdisciplinar.

Diante da UNESCO (2016), a educação integral é aquela que constrói os recursos humanos necessários para que o individuo, se torne cada vez mais um ser produtivo.E, dentro dessa produtividade esse individuo continua dentro de um ciclo constante de aprendizagem, com autonomia para solucionar situações problemas que são comuns nas mais diversas situações do cotidiano.Essas são as principais características de um ensino integral, devendo sair das pautas e ir para as experiências cotidianas que são construídas dentro e fora dos espaço escolares.

Ainda dentro do documento da UNESCO (2016), é feito uma analise que a educação integral visa alcançar a criatividade e a convivência harmônica com os nossos semelhantes e com a natureza. Percebe-se a grande relevância que o ensino tem em se tronar cada vez mais integral, possuindo objetivos e metas rigorosas para serem alcançadas em prol de uma educação muito mais significativa.

Para Freire (2005), o elemento chave que serve de fio condutor para um ensino muito mais significativo e integrador se resume na palavra "diálogo". Esse importante 
caminho deve ser trilhado consciência e sabedoria. Porque é através dele que é realizado o trabalho de conscientização e de reeducação do sujeito. Dai, surge a suma importância do desenvolvimento e do exercício continuo dentro dos espaços de aprendizagem que estimulem o dialogo aberto.

Para Barbosa (2016), a educação não pode ser conceituada como um depósito de conhecimento armazenado, com é essa visão pobre que muitos que não conseguem enxergar a dimensão que o termo educação tem. Nesse sentido a má formação profissional, a falta de afinidade, de interesse, de afeto pela educação torna o processo dificultoso,no que se refere a educação integral e holística.

Ainda no pensamento de Barbosa (2016), o conhecimento não se concentra na Ciência e, sim nas ideais próprias que o sujeito vem a desenvolver. Por fim, o autor conclui seu pensamento dizendo que o homem sábio não um armário de sabedoria, ele é um agente transformador e reflexivo dentro de sua realidade.

Ao analisar o documento da UNESCO (2016), "Repensar a Educação Rumos a um bem comum mundial"? Existe uma infinidade de pontos a serem explorados. Um deles são os conhecidos quatro pilares educacionais contidos no relatório Delors, em 1996, sendo os seguintes: 1) Aprender a conhecer; 2)Aprender a fazer; 3) Aprender a ser; 4) Aprender a viver.Não é nada fácil, concretizar esse desafio educacional proposto por Delors, esse desafio deve ser trabalhado cuidadosamente, onde cada ação deve ser subsidiada por uma intervenção, tendo uma minuciosa execução com experiência e habilidade.

O papel dos pilares educacionais é primordial para formação de uma educação integral e humanizada. Inicialmente o primeiro pilar representa o conhecimento de mundo que usa com recurso os conhecimentos prévios que são inerentes a todos os seres humanos. O segundo pilar refere-se ao conhecimento técnico, uma importante área que deve ser bem embasada. O terceiro pilar significa um alto conhecimento sobre si mesmo, fazendo recordar as palavras de Platão "conhece-te a ti mesmo". Por último aparece à importância de vivermos em sociedade, um componente essencial para que haja uma vida harmônica entre os seres humanos.

A execução dessa importante ferramentas consiste na consolidação de uma educação de fato integral, esse desafio é possível quando houver de fato prioridade, no que se refere à educação, e essa consolidação já é realidade em algumas escolas do nosso país.É responsabilidade de todos fazer acontecer e fluir esses pilares desde a sociedade civil, órgãos, corpo docente, comunidade escolar e discentes. 
É preciso que aconteça na prática todo esse processo, permitindo uma educação significativa e de acesso para todos mesmo em meio a tantas situações adversas que são obstáculos encontrados pelo caminho, mas que não devem nos paralisar ou intimidar.

\section{EDUCAÇÃO E MORAL}

Mudanças ocorreram dentro do sistema educação, principalmente no requisito das TICs. Houve avanços e também alguns retrocessos como, por exemplo, a ausência da ética e da moral dois importantes princípios, que não tem sido priorizado como deveriam. Infelizmente a sociedade tem deixando de valorizar alguns princípios essenciais para a vida escolar e social, ou não tem dado a real importância que eles merecem. A esse problema também é designado o nome desumanização do sujeito, um grave problema que requer as devidas intervenções. Isso que dizer que muitas famílias e escolas têm fracassado no processo educacional de seus filhos e alunos por faltarem com o alicerce da ética e da moral.

Fundamentado nessa necessidade faz nos lembrar da educação grega que possuía um grande rigor no contexto de priorizar os aspectos cristãos, os valores e os costumes que desde muito cedo era trabalhado com autoridade e seriedade.

A presença da ética e da moral faz todo um diferencial dentro de um contexto social. Se desde a educação infantil uma determinada criança é ensinada dentro de um perfil ético, a tendência dela se tornar um ser humano adulto mais ético, mais maduro e consciente de suas ações é bem maior do que um indivíduo, que não recebeu uma educação ética ou moral com rigor por parte da instituição escolar ou o grupo familiar. Esse processo é também chamado de humanização do sujeito, que ocorre por meio das interações sociais e do conhecimento cientifico.

O trabalho desenvolvido por Kohlberg (1992) traz como reflexão o desenvolvimento moral do sujeito, significa na prática atribuir a relevância para os valores partilhados, uma situação problema muito comum na sociedade atual à ausência deles.

Analisando o pensamento do filósofo alemão Jürgen Habermas (1984) diz que é necessário adotar um modelo ético e moral dentro das sociedades, e isso reflete positivamente no contexto escolar. Alicerçando nisso nossa realidade educacional requer uma atenção mais especial no que se refere à educação ética e moral. Com o intuito de formar uma sociedade mais ética que prioriza valores e princípios.

Os estudos de Kohlberg (1992) ressalta ainda a relevância da construção de uma consciência moral, um importante aspecto que deve ser trabalhado cuidadosamente na formação do caráter e da identidade de nossos alunos. Diante dessa carência Kohlberg (1992) diz que é na primeira infância que os valores éticos devem ser introduzidos.E nessa parceria 
escola e família devem está unidas nessa importante construção do sujeito que tem o objetivo central de humanizar e educar o sujeito.

A vida em sociedade requer que sejam assimiladas determinada regras e, normas para que haja um determinado controle no cotidiano das relações humanas. Kohlberg (1992) traz em seus estudos a importância da coletividade atribuindo que "nós" tem maior força do que o "Eu".Essa importante expressão revela uma grande necessidade de agir e viver em grupo e, que a união sempre é bem vinda dentro e fora do contexto escolar.

A verdadeira educação integral é aquela que auxilia na formação da identidade do sujeito, trazendo um espírito de coletividade, tão necessário para a formação da cidadania.

O desafio da educação integral nos dias atuais está dentro das desigualdades sociais que variam desde a raça, cor,classe, sexo, credo e valores culturais.Então, nessa dificuldade é necessário traçar metas para que sejam trabalhados todo esse contexto, sem ferir esses princípios citados acima.

A educação moral é inicialmente de responsabilidade do grupo familiar, porque o primeiro contato que o ser humano desenvolve é com a instituição familiar, mas a escola tem também uma importante participação nessa formação tão relevante para que a personalidade do sujeito seja passo a passo constituída. O objetivo da educação moral é ampliar a capacidade cognitiva do sujeito, dando as condições necessárias para que determinadas competências e habilidades sejam desenvolvidas.

Para a UNESCO (2016), essa educação moral é também denominada de educação humanista que tem o intuito central de propiciar o desenvolvimento do indivíduo levando em conta vários aspectos. De acordo com a UNESCO (2016), esse modelo educacional chamado de humanista tem um importante princípio: O respeito pela vida. Um tópico que deve ser levado muito a sério, já que a sociedade atual tem em parte menosprezado ou negligenciado esse principio divino, que traz uma reflexão tão proveitosa, para uma melhor educação de nossas crianças.Educar por meio dessa teoria proposta aqui, traz um sentimento de afetividade, humanismo e de valorização,Sentimentos esses que estão cada vez mais são escassos e precisa ser resgatados.

Ainda dentro do contexto de educação humanista a UNESCO (2016), traz outros importantes temas que devem ser transversais tais como: Dignidade humana, Igualdade de Direitos, Justiça social, Respeito pela diversidade cultural, Solidariedade etc. Todos esses aspectos são primordiais para uma educação mundial que seja mais integral, cabe cada instituição escolar ser sábia e introduzir um trabalho interdisciplinar que envolva essas 
temáticas e, a partir daí, seja feito um trabalho de conscientização e de reeducação desde a educação infantil, dando sequencia por todo o processo de escolarização.

O documento da UNESCO (2016), que é uma das bases teóricas desse estudo classifica o termo educação como um bem comum para todos. E, dentro desse conceito se faz necessário a implantação de políticas públicas que trabalhem essa ideia e conscientizem a todos que esse bem comum chamado de educação deve ser integral.Respeitando os direitos, deveres e toda a diversidade que existe no mundo globalizado.Por último conclui essa fala dizendo que Educação e Moral são dois elementos complementares que não podem ser dissociados

\section{EDUCAÇÃO E SUSTENTABILIDADE}

Ao abordar a temática de educação integral existem muitos outros elementos que deve ser incorporados a ela. Um desses elementos é a educação ambiental que tem o grande desafio de auxiliar na formação de uma sociedade mais sustentável. O cenário escolar e ambiental devem ser trabalhados em parceria, porque homem e natureza são também dois elementos indissociáveis, uma vez que é impossível a sobrevivência da espécie humana, sem o solo, a água e a luz. Sendo que tais elementos vêm sofrendo sérias agressões pela ação humana, necessitando de sérias intervenções.

A educação integral só será uma ampla realidade, quando houve uma prática continua e intensiva de conservação dos elementos naturais que são responsáveis pela existência da espécie humana dentro do globo terrestre, a isso é dado o nome de consciência ambiental e sustentável, uma das metas da educação humanizada e integral. Dentro dessa realidade a UNESCO (2016), diz que indispensável o respeito à conservação da fauna e flora bem comum a toda humanidade. Sendo necessária a maior implantação de políticas públicas com caráter ambiental, que foque a conservação e a preservação desses importantes recursos, que garantirão a vida das futuras gerações.

Faz-se necessário uma parceria entre princípios morais contextualizados com os valores éticos e isso é muito válido no requisito educação ambiental. Para a UNESCO (2016), a natureza se define com uma grande diversidade cultural que o documento "Repensar a Educação. Rumo a um bem comum mundial"? Apresenta-nos como uma riqueza da humanidade. Mediante a tudo isso é necessário à conservação dessa riqueza, que cada vez mais tem sido empobrecida, pela perda parcial ou até mesmo total de alguns elementos naturais, que são de extrema importância para a vida no planeta. 
Em meio a Modernidade tecnológica que a sociedade vive não se tem dado a importância pelas questões ambientais. Então, surge a necessidade de inserir ética, moral e sustentabilidade ambiental dentro da educação integral e humanizadora.

Para SGRÓ (2007), o futuro da humanidade está intimamente ligado com as questões ambientais, e esse futuro deve ser a preocupação não de um indivíduo, ou de parte da sociedade, mas uma preocupação de todos os habitantes do planeta. É ai, que a escola entra em ação com um papel de conscientização e de ação em prol dessa luta incansável que é a salvação do planeta. E, sem sobra de dúvida a educação e a reeducação do sujeito é o caminho a seguir.

Na construção de uma sociedade mais sustentável, numerosos são os obstáculos que sevem de empecilhos. Dentre eles o crescimento econômico excessivo, que visa o capitalismo acima de tudo, no qual tem sido um grande mal para a sociedade contemporânea, impedindo o progresso dessa construção. A UNESCO (2016) critica os "padrões insustentáveis de produção e consumo apontam para contradições fundamentais em um modelo dominante de desenvolvimento centrado no crescimento econômico" (UNESCO, 2016, p. 25).

Alicerçado nisso um dos graves problemas da humanidade é o consumismo extravagante nos mais diversos aspectos da vida cotidiana moderna. Todos esses excessos agridem ao meio-ambiente, causando problemas ambientais de grande preocupação para humanidade como o aquecimento global que tem resultados em desastres naturais que tem destruído a vida de muitos.

Para (BANNWART JÚNIOR, et al. 2017) o desenvolvimento econômico traz benefícios para os grandes empresários e empreendedores e maléficos para a população mundial com um todo.A qualidade de vida está associada com o controle desse desenvolvimento econômico,porém ele se encontra em um nível de crescimento desenfreado, onde o homem movido pela ganância pensa só em gerar lucros.Falam até na compra de terras no planeta vermelho e uma possível colonização. Quando vier uma total destruição dos elementos naturais do planeta terra, e a vida não for mais possível por aqui.

O consumismo extravagante é um obstáculo que impedem a conscientização sócia ambiental dentro de uma perspectiva de sustentabilidade, uma vez que o capitalismo é o que impera. Diante dessa realidade VEIGA (2013), afirma que muitos países já tem se conscientizado, acerca das consequências que a ação humana, pode causar direta ou indiretamente no meio ambiente, e isso a curto e em longo prazo. Com base nessa explicação muitos países têm feito o seu papel em busca da sustentabilidade, isso pode ser exemplificado 
com a Suíça um dos primeiros países da Europa a exigir o uso de catalisador e, além disso, os suíços são adeptos de andar muito de bicicleta ao invés de carros que polui. Um segundo modelo de sustentabilidade é Luxemburgo onde é investido pesado em sustentabilidade como prova disso tem expandido cada vez mais os são setores de energia solar.

Essa importante ação de agir e viver de forma ecologicamente correta só traz benefícios. Tais mudanças devem ser drásticas porque grande é o numero de pessoas que vivem no comodismo. Essas pequenas atitudes tem o intuito de obter as menores taxas possíveis de desigualdades, controle consumismo excessivo por meio de medidas severas para aqueles que transgridem as normas pré-estabelecidas, incentivo para trabalhos sociais que envolva a reciclagem e o melhor auxilio aos países que sofrem com a fome e a pobreza. Essas importantes ações, já é a realidade em alguns países que são exemplo de padrão sustentável no mundo.

Entende-se que para uma educação sustentável e integral é primordial o maior investimento em Educação com ações sérias que Envolva as questões ecológicas, reciclagem do lixo, racionamento de água e energia e também um controle do crescimento populacional mundial etc. Todas essas medidas e outras devem fazer parte das pautas de políticas públicas e da realidade no nosso currículo escolar.

Analisando em parte o documento "Repensar a Educação Rumo a um bem comum"?As denuncias são gritantes dentre elas o consumo de água potável duplicou nas ultimas décadas o que pode gerar uma terceira guerra mundial em busca do liquido mais importante para a sobrevivência da espécie humana. Todos esses questionamentos devem ser discutidos e ações preventivas deve se concretizar dentro do cotidiano das pessoas em prol de um futuro mais equilibrado.

A natureza ao mesmo tempo em que é afetada, através da ação humana que fere e a destrói. Ela também reage de acordo com (UNESCO, 2016, p. 25) "Estima-se que, até 2030, a demanda por alimentos terá um aumento de pelo menos 35\%, a demanda por água $40 \%$ e a demanda por energia 50\%". Aqui é descrito os principais motivos que são capazes de provocar uma revolução mundial e, também a morte de milhares de pessoas em todo o mundo. Então, a escola surge como um instrumento pedagógico de conscientização que busca trabalhar não só conceitos e teorias cientificas, mas que deve focar a respeito da valorização e o respeito a vida como já foi mencionado anteriormente.

Toda essa questão de sustentabilidade para muitos ainda parecem um discurso fantasioso de ambientalista fanático, mas a realidade está estampada na face da humanidade como confirma os estudos de VEIGA (2013), ao fazer um comparativo que consumismo dos 
humanos em 365 dias a biosfera precisa de um ano e meio para regenerar-se totalmente daquela agressão, isto, é a humanidade está com um saldo negativo gigantesco com a mãe natureza. Implica que é tempo de agir por meio de ações e práticas educativas continua que venha amenizar esses impactos ambientais.

A própria UNESCO (2016), aponta parte da resolução de toda essa situação problema que é tão grave e preocupante. É preciso focar na qualidade da educação e na construção aprendizagem que sejam mais significativas onde haja uma mobilização em massa da população, através de práticas de defesa as questões sócio ambientais com responsabilidade e respeito à vida, sem ferir outro de forma harmônica, e isso é possível quando a soma de forças em prol de um bem comum um planeta mais sustentável.

E, dentro dessa necessidade a arma principal é a conscientização, e a escola funciona com um agente importante nessa construção como confirma SGRÓ “a Educação é uma arte, cuja prática precisa ser aperfeiçoada por várias gerações" (SGRÓ, 2007, p.60). Essas palavras descrevem com perfeição o tamanho o papel social que a educação tem sobre os humanos, aperfeiçoar novas ações em prol da conservação da espécie humana no planeta.

Para a UNESCO (2016), a educação é uma concretização de um direito que é fundamental, e esse direito não pode ser negligenciado como tem sido em muitos países, onde milhares de crianças e adolescente sofrem sem o acesso a esse direto básico. Exemplo disso temos, o Brasil que de acordo com uma Pesquisa Nacional por Amostra de Domicílio (PNAD) em parceria com o programa Todos Pela Educação em 2015, ainda existia 2.486.245 crianças e adolescentes de quatro e 17 anos fora da escola cerca de $6 \%$ do alunado.

Baseado em analises feitas no documento da UNESCO a educação integral só será de fato algo concreto quando houver a implantação de um governo policêntrico, ou seja, nesse sistema governamental os bens coletivos e problemas comuns deixem de ser de ninguém, para serem de todos. Essa belíssima ideia de compartilhar com o outro, de compaixão, de amor ao nosso próximo e de preservar o nosso maior patrimônio: O planeta. Para efetivar esse tipo de governo, se faz necessário um processo árduo de reeducação de valores e princípios, que tem se perdido ao longo dos anos. É preciso também que a educação formal ofereça respostas satisfatórias para convencer de verdade.

Por fim, a UNESCO (2016), aponta duas importantes medidas. A primeira delas é imprescindível enfrentar os inúmeros desafios que essa aprendizagem de valores e princípios enfrentará em seu processo. E, a educação deve ser construída como um equilíbrio entre o respeito pela pluralidade e valores universais. Todos esses questionamentos são grandiosos e complexos, mais são necessários, para que num futuro mais próximo possamos, 
formar nossas crianças dentro de um novo patamar educacional,valorizado o processo de humanização pela educação.

Repensar na educação para a cidadania é uma necessidade, uma vez que se almeja construir uma educação integral. Esse trabalho só será possível com a colaboração dos poderes constituídos, sociedade, comunidade, docentes e discentes somando forças em prol desse objetivo maior: A educação para cidadania.

\section{RESULTADOS}

Há muitos resultados positivos alcançados, após a inserção da educação integral em nossas escolas. Em um documentário de Vagner (2012), mostra com propriedade, tais resultados. Inicialmente é relatado que os municípios que executam essa modalidade educacional, obtiveram significantemente uma maior aproximação das relações interpessoais de pais, cidadãos, professores e alunos. Em seguida houve um salto qualitativo no IDEB, uma das grandes preocupações no requisito resultados escolares.

Vagner (2012), em um dos seus textos expressa-se dizendo que a escola, não pode ficar refém de quatro paredes, deve extrapolar seus limites e ir muito além de seus muros. Outro resultado importante, que vem sido trazido pela educação integral é que os professores, não podem jamais ficarem presos aos seus conteúdos didáticos e a rotina da sala de aula. É importante atuarem como educadores comunitários com maior intensidade, auxiliado cada vez mais na identificação de problemas de aprendizagem e buscando as possíveis soluções. Atuar ainda, como investigadores para mapear espaços, pessoas e oportunidades, que possam se tornar parceiros e atores ativos na construção da educação integral. É sem dúvida um trabalho árduo, porém necessário quando se objetiva uma educação mais integradora.

O autor abre um parêntese para o beneficio da contextualização que deve ocorrer dentro do ensino integral, pois aprender os conteúdos curriculares de forma significativa exige uma relação com as diferentes vivências humanas. Acrescenta que a escola para ser integral, deve estabelecer relações com os espaços diferenciados como: praças, quadras de esportes, lojas, igrejas, postos de saúde etc.

Um ponto forte nesse processo de educação integral apontado por Vagner (2012) é a multidisciplinaridade. Uma estratégia que já, vem sendo adotadas por muitas escolas em Belo Horizonte e Rio de Janeiro. O exemplo do sucesso de uma escola integral também já é realidade em Apucarana no Paraná, lá o modelo de educação integral é obrigatório em todas as escolas municipais. E, isso deveria ser realidade em todo o país, mas infelizmente inúmeros são os fatores que impedem essa grande conquista. 
De acordo com a da fala de Heloísa Mesquita (2012), uma das coordenadoras de um projeto de educação integral. A escola para ser integral precisa experimentar e inovar. Um dos segredos da educação integral é a atuação polivalente dos professores. Em suas palavras ela se refere que o mesmo educador da área das ciências exatas deve percorre pelos demais campos do conhecimento, e nunca ficar presos na mesma disciplina de formação.

Heloisa Mesquita (2012), ainda acrescenta que a educação integral vai de encontro ao efetivo desenvolvimento da sociedade. Dando continuidade a fala de Vagner (2012), um dos responsáveis do sucesso do ensino integral é a inserção das disciplinas diferenciadas, que são trabalhadas de forma lúdica, envolvendo as mais diversificadas áreas da robótica, ciclos de leitura, dança, musica teatro, cinema etc.

Outro modelo de sucesso de uma educação integral é encontrado em BH, e ficou conhecido como cidade-educadora. Nessas escolas os objetivos são direcionados para a prática de trilhas educativas, onde são realizados atividades culturais, esportivas e de formação cidadã. É a chamada educação em movimento como diz a própria etimologia da palavra educação. Todos esses são resultados reais de práticas educativas, que são possíveis e que serve de exemplo e de inspiração, para que seja adotado o modelo padrão em todas as escolas por um ensino muito mais integral e integrador.

\section{CONSIDERAÇÕES FINAIS}

Diante de tudo que aqui foi exposto, entende-se que a educação é um patrimônio riquíssimo e que a mesma é um instrumento de transformação e lapidação do homem. Esse importante patrimônio deve ser partilhado de forma integral na vida do sujeito, para que determinadas competências e habilidades, sejam de fatos consolidadas daí, surge a carência de construir uma educação que seja mais inclusiva e integradora.

Nesse sentido, a educação é muito mais do que a apropriação de conceitos, regras e meras memorizações. Educar tem uma amplitude gigantesca, que vai desde a formação cientifica passeando pelos aspectos cognitivos, e por fim por todas as estruturas da vida humana.

Educação e cidadania num contexto de ensino integral são dois elementos inseparáveis então, é necessário um reeducar, onde o ser humano seja exercitado a conviver em sociedade sem ferir o outro, ou tirar o direito do outro, tendo respeito pela muitas diversidades que existem.

Não se pode esquecer que os valores éticos e os princípios morais tem uma relevância extrema no contexto de uma educação integral, pois eles aqui funcionam com fios condutores nesse processo tão desafiador, e ao mesmo tempo tão necessários. 
Obviamente que obstáculos surgiram, desde as diversidades e a pluralidade de opiniões, principalmente ao se iniciar um processo de escolarização tão desafiante como esse , que é propiciar uma educação integral em meio a tantos conflitos das mais diversas naturezas ,que se chocam ao tempo todo.

A educação integral se define aqui como oferecimento das condições básicas, para que o ser humano possua uma formação plena não só pautados dentro do conteudismo ,que lhe obrigatório dentro do currículo escolar.Mas que ele possua os Parâmetros que dão sustentabilidade para os valores e princípios como a tolerância, o respeito, à solidariedade e a afetividade, a isso chamamos de humanização do sujeito.

O modelo desse sistema integral foi apresentado pela UNESCO (2016), cabe agora à participação de todos, para que os objetivos de uma educação mais integradora sejam de fato alcançados.

Os desafios encontrados nesse processo são grandes muralhas que devem ser superados com estratégia e sabedoria. Por que é um direito humano e universal que a União, Estado e Municípios proporcionem um ensino integral de qualidade.

Responsabilidade Integral é a palavra chave que é capaz de propiciar esse modelo educacional, partindo não do individualismo, mas do coletivo em prol de um bem comum: A educação.

Destacou-se ainda que a moral, a ética e a sustentabilidade devem caminhar em parceria, para a formação e construção de um ensino integral, movido por meio de ações, medidas e políticas públicas que contemple a realidade educacional, que temos e amenizem os mais diversos problemas nela encontradas. Em resposta ao objetivo e ao problema da pesquisa, foi possível obter uma ampla visão, acerca dessa importante temática, trazendo relevantes contribuições que serão de grande utilidade para o exercício da prática docente.

Por último para obter uma educação de fato efetiva, significativa e integradora é necessário à assídua participação de todos os órgãos que regem a educação. Como sugestão, indica-se que novos estudos sejam realizados dentro dessa importante temática para que seja, construída uma visão mais ampla e esclarecedora, acerca da relevância e da eficácia de uma educação integral, que tanto se almeja construir.

\section{REFERENCIAS}

ALENCAR, Vagner. Estudo mostra importância da educação integral para a criatividade na infância. Disponível em: http://porvir.org> - 10/1/2012.

FERREIRA, Aurélio Buarque de Holanda.Novo dicionário da língua portuguesa.3.ed. rev. e atual.SP:Fundação Dorina Nowil para cegos 
BANNWART JÚNIOR, Clodomiro José; CATARINO, Dílson; LIMA, Gleiton; NUNES, Liliane. Responsabilidade Integral. Metodologia estratégica para o desenvolvimento pessoal, corporativo e educacional. Londrina/PR:Midiograf, 2017.

BARBOSA, Rui. Oração aos Moços. São Paulo: Editora HB, 2016.

FREIRE, Paulo. Pedagogia do Oprimido. Rio de Janeiro: Paz e Terra, 2005, 44a edição.

HABERMAS, Jürgen. The Theory of Communicative Action, volume I. Boston, Beacon Press, 1984; volume II, Boston, Beacon Press, 1987.

Kohlberg, L. (1992). Psicología del desarrollo moral. Bilbao Spain: Desclée de Brouwer. MARTINS, Heloisa Helena T. de Souza. Metodologia qualitativa de pesquisa. Educação e Pesquisa, São Paulo, v.30, n.2, p. 289-300, maio/ago. 2004.

SGRÓ, Margarita. Educação pós-filosofia da história: racionalidade e emancipação. São Paulo: Cortez, 2007.

UNESCO. Repensar a Educação. Rumo a um bem comum mundial? Tradução de Rita Brossard. Brasília/DF: UNESCO Brasil, 2016.

VEIGA, José Eli da. A desgovernança mundial da sustentabilidade. São Paulo: Editora 34, 2013. 